\title{
Efeito da frequência de ordenhas de vacas mestiças na rentabilidade da atividade leiteira
}

\author{
[Effect of frequency of milking crossbred cows in the profitability of dairy farming]
}

\section{"Artigo Científico/Scientific Article"}

\author{
Fernando Etiene Pinheiro Teixeira Júnior ${ }^{1, *}$, Marcos Aurélio Lopes ${ }^{2}$, \\ José Reinaldo Mendes Ruas $^{3}$, Maria Dulcinéia Costa ${ }^{3}$, Vicente Ribeiro Rocha Júnior ${ }^{3}$
}

\begin{abstract}
${ }^{1}$ Departamento de Ciência da Administração, Universidade Estadual de Montes Claros, Montes Claros-MG, Brasil.
${ }^{2}$ Departamento de Medicina Veterinária, Universidade Federal de Lavras, Lavras-MG, Brasil.

${ }^{3}$ Departamento de Ciências Agrárias, Universidade Estadual de Montes Claros, Janaúba-MG, Brasil.

*Autor para correspondência/Corresponding author: E-mail: fernandoetiene82@ hotmail.com
\end{abstract}

\section{Resumo}

Analisou-se, por meio de simulação, o efeito do uso do manejo de quatro ordenhas no início da lactação de vacas mestiças na rentabilidade da atividade leiteira de um sistema de produção de leite. Durante o período chuvoso, na época do verão, as vacas foram mantidas em pastos e, durante o período da seca, foram confinadas com o uso da cana-de-açúcar in natura enriquecida com ureia e sulfato de amônio. A referência zootécnica foi do rebanho composto por vacas F1 Holandês x Gir da Fazenda Experimental de Felixlândia (FEFX) da Empresa de Pesquisa Agropecuária de Minas Gerais (EPAMIG), localizada no município de Felixlândia-MG, região central do estado. $\mathrm{O}$ inventário bem como as despesas, as receitas e os demais dados foram cadastrados no software CUSTO BOVINO LEITE 1.0, visando obter a análise de rentabilidade. O uso do manejo de quatro ordenhas no início da lactação melhorou a rentabilidade de um sistema de produção de leite com vacas F1 Holandês x Gir.

Palavras-Chave: bovinocultura leiteira, lucratividade, ordenha, simulação.

\begin{abstract}
The effect of the use of a system with four milkings in early lactation of crossbred cows on the profitability of dairy farming of a milk production system was analyzed by means of simulation. During the rainy season, in the summer season, the cows were kept on pastures and during the dry season, they were confined with the use of in natura sugar cane enriched with urea and ammonium sulfate. The husbandry 1 reference was from the herd composed of Holstein x Gir F1 cows from the Experimental Farm of Felixlândia (FEFX) of the Agricultural Research Corporation of Minas Gerais (EPAMIG), located in the municipality of FelixlândiaMG, central region of the state. The inventory, as well as expenditures, revenue and the other data were registered on COST BOVINE MILK 1.0 software aiming to obtain profitability analysis. The use of a frequency of four milkings in early lactation improved the profitability of a system of milk production with F1 Holstein x Gir cows.
\end{abstract}

Key-words: dairy cattle, profitability, milkings, simulation.

\section{Introdução}

Os índices produtivos interferem significativamente nos indicadores de rentabilidade. Considerando a importância de otimizar os custos de uma unidade produtiva através do aumento de sua produtividade, faz-se necessário elevar a produção leiteira paralelamente com a intensificação da frequência diária de ordenhas. De acordo com Wall e McFadden
(2007), o aumento da frequência de ordenhas no início da lactação promove o aumento e a manutenção da produção de leite que está relacionada ao aumento da proliferação e diferenciação celular e com possível redução nas taxas de apoptose, a qual é provavelmente regulada por mecanismos locais sensíveis ao aumento da frequência de ordenhas. 
O aumento da quantidade de ordenhas de vacas mestiças Holandês-Zebu tem melhorado a performance produtiva, fato que pode ser favorável para sistemas de produção com esse tipo de animal, visto que a persistência da lactação e o volume de leite diário produzido, quando comparado à das vacas holandesas puras, é menor e fazem com que a produtividade diminua. Entretanto, segundo Lima et al. (2011), o manejo de quatro ordenhas diárias nos primeiros 21 dias de lactação de vacas mestiças Holandês-Zebu proporciona aumento de produção de leite de dois litros/dia, perfazendo $522 \mathrm{~kg}$ na lactação total $(4.489 \times 3.967 \mathrm{~kg})$, o que representa incremento de $13,15 \%$ na produção de leite por vaca em lactação. De acordo com Ruas et al. (2011), o manejo de quatro ordenhas nos primeiros 21 dias da lactação, com vacas primíparas F1 Holandês x Zebu aumenta $514 \mathrm{~kg}$ na lactação total $(3.488 \times 2.974 \mathrm{~kg})$, o que representa incremento de $17,28 \%$ na produção total. Ainda segundo esses autores, essa tecnologia tem se mostrado zootecnicamente positiva uma vez que ocorre aumento significativo na produção de leite, permanecendo a dúvida quanto à eficiência econômico-financeira.

Aliado a esse incremento, a maior utilização da estrutura física de produção permite diminuir o custo unitário do leite pelo aumento do volume produzido numa mesma estrutura produtiva (Lopes et al., 2006). Outro fator importante para o resultado econômico-financeiro do sistema produtivo é o fato de não haver necessidade de implementar mais turnos de ordenha, mantendo-se dois turnos diários (Lima et al., 2011).

Segundo Barbosa et al. (2013), após ampla revisão sobre o tema, o aumento da frequência de duas para três ordenhas promove um incremento médio de $16,75 \%$ na produção de leite, entretanto, segundo eles, outros fatores devem ser avaliados antes de se tomar a decisão, sendo o custo um aspecto muito importante. Assim deve-se considerar as despesas com produtos (pré e pósdipping, óleo para bomba de vácuo, papel toalha e detergentes, além de outros), com consumo de energia elétrica (lâmpadas, motor elétrico da bomba de vácuo e aquecedor de água), com materiais e equipamentos (balde de leite, caneca de fundo preto e coador de leite, dentre outros), com mão de obra (hora extra e adicional noturno) e com o aumento do consumo de alimento concentrado pelas vacas.

Diante do abordado, objetivou-se analisar o efeito do uso do manejo de quatro ordenhas no início da lactação de vacas mestiças (F1 Holandês $\mathrm{x}$ Zebu) na rentabilidade da atividade leiteira de um sistema de produção de leite.

\section{Material e Métodos}

A referência zootécnica foi do rebanho composto por vacas F1 Holandês x Gir da Fazenda Experimental de Felixlândia (FEFX), da Empresa de Pesquisa Agropecuária de Minas Gerais (EPAMIG), localizada no município de Felixlândia-MG, região central do estado. O clima é classificado, segundo Köppen, como tropical de savana, com duas estações bem distintas: inverno seco (maio a outubro) e verão chuvoso (novembro a abril). A precipitação pluviométrica média anual é de $1.126 \mathrm{~mm}$.

No sistema de produção utilizado, durante o período do inverno seco as vacas foram confinadas e alimentadas com cana-de-açúcar (Saccharum officinarum L.) in natura enriquecida com ureia $\mathrm{e}$ sulfato de amônio por seis meses. Durante o período do verão chuvoso, as vacas foram mantidas, por seis meses, em piquetes formados por gramíneas Brachiaria decumbens e Brachiaria brizanta.

A suplementação concentrada foi realizada durante a ordenha e de acordo com a produção de leite das vacas, na relação de $1 \mathrm{~kg}$ para $3 \mathrm{~kg}$ de leite produzido, a partir de $5 \mathrm{~kg}$ de leite. A água, em bebedouros e/ou em represas, e a mistura mineral, em cochos cobertos, foram ofertadas ad libitum.

Durante 30 dias do período pré-parto, as vacas recebiam diariamente $0,8 \mathrm{~kg}$ de concentrado no inverno seco. Decorridas 24 horas do pós-parto, as vacas foram conduzidas para o sistema de vacas em produção. Aquelas com produção acima de $8 \mathrm{~kg}$ de leite por dia foram ordenhadas duas vezes ao dia e as vacas com produção entre 5 e $8 \mathrm{~kg}$ de leite, apenas uma vez. Vacas com produção abaixo de $5 \mathrm{~kg}$ de leite por dia foram soltas com a cria e, quando atingiam 90 dias de pré-parto, eram separadas dos bezerros. Os bezerros em amamentação, oriundos de cruzamento terminal, foram levados à sala de ordenha para estimular a descida do leite e após o desmame, que ocorreu, em média, aos 276 dias foram comercializados.

Como referência administrativa e para efeito de cálculo, considerou-se um sistema hipotético de produção de leite com 68 vacas F1 Holandês x Gir, ordenhadas duas vezes ao dia por dois profissionais treinados. A sala de ordenha do tipo espinha de peixe com fosso e ala dupla comportava quatro vacas de cada lado e a ordenhadeira mecânica 
utilizada foi do tipo sistema aberto com "balde ao pé”.

Os cálculos deste estudo foram baseados em dados produtivos (Tabela 1) e reprodutivos (Tabela 2) provenientes do sistema de produção de leite com vacas F1 Holandês x Gir da FEFX - EPAMIG. Foram considerados os índices técnicos e manejo de vacas F1 Holandês x Gir encontrados na literatura (Tabela 3), nos valores relacionados à comercialização de animais e produtos e nos indicadores mercadológicos (Tabela 4), em cotações de preço obtidas no Boletim CEPEA (Centro de Estudos Avançados em Economia Aplicada - Região de referência de Minas Gerais) e nos dados econômico-financeiros deste sistema hipotético de produção de leite durante o período de 01 de maio de 2011 a 30 de abril de 2012.

Tabela 1. Valores de desempenho produtivo de vacas F1 Holandês x Gir em diferentes ordens de partos utilizados neste estudo.

\begin{tabular}{lclcc}
\hline $\begin{array}{c}\text { Ordem de } \\
\text { parto }\end{array}$ & $\begin{array}{c}\text { Produção total } \\
(\mathbf{k g})\end{array}$ & $\begin{array}{c}\text { Produção média } \\
\text { diária }(\mathbf{k g})\end{array}$ & $\begin{array}{c}\text { Duração da } \\
\text { lactação }(\text { dias })\end{array}$ & $\begin{array}{c}\text { Produção média } \\
\text { no pico }(\mathbf{k g})\end{array}$ \\
\hline Primeira & $2.426,36^{\mathrm{a}} \pm 710,45$ & $8,14^{\mathrm{a}} \pm 2,03$ & $297,97^{\mathrm{a}} \pm 49,55$ & $13,23^{\mathrm{e}} \pm 3,13$ \\
Segunda & $3.048,47^{\mathrm{d}} \pm 833,12$ & $10,82^{\mathrm{f}} \pm 2,39$ & $280,96^{\mathrm{b}} \pm 42,16$ & $17,32^{\mathrm{d}} \pm 8,31$ \\
Terceira & $3.391,39^{\mathrm{c}} \pm 895,43$ & $11,84^{\mathrm{e}} \pm 2,26$ & $285,57^{\mathrm{b}} \pm 50,39$ & $18,06^{\mathrm{d}} \pm 2,84$ \\
Quarta & $3.646,20^{\mathrm{b}} \pm 874,48$ & $12,92^{\mathrm{d}} \pm 2,16$ & $281,29^{\mathrm{b}} \pm 43,72$ & $19,17^{\mathrm{c}} \pm 3,25$ \\
Quinta & $3.886,23^{\mathrm{a}} \pm 899,45$ & $14,00^{\mathrm{c}} \pm 2,61$ & $278,00^{\mathrm{b}} \pm 43,13$ & $20,76^{\mathrm{b}} \pm 6,65$ \\
Sexta & $4.005,36^{\mathrm{a}} \pm 938,86$ & $14,46^{\mathrm{b}} \pm 2,31$ & $276,29^{\mathrm{b}} \pm 43,97$ & $21,28^{\mathrm{b}} \pm 3,53$ \\
Sétima & $4.033,58^{\mathrm{a}} \pm 810,55$ & $15,20^{\mathrm{a}} \pm 2,51$ & $265,94^{\mathrm{c}} \pm 34,05$ & $22,18^{\mathrm{a}} \pm 3,21$ \\
Oitava & $3.961,23^{\mathrm{a}} \pm 644,66$ & $15,33^{\mathrm{a}} \pm 1,97$ & $259,24^{\mathrm{c}} \pm 34,29$ & $22,13^{\mathrm{a}} \pm 2,90$ \\
Nona & $3.881,94^{\mathrm{a}} \pm 669,57$ & $15,51^{\mathrm{a}} \pm 2,69$ & $251,79^{\mathrm{d}} \pm 29,67$ & $22,23^{\mathrm{a}} \pm 3,10$ \\
\hline Médias seguidas de letras minúsculas distintas na mesma coluna diferem $(\mathrm{P}<0,05)$ pelo teste Scott-Knott \\
Fonte: Pereira (2012).
\end{tabular}

Tabela 2. Índices reprodutivos das vacas F1 Holandês x Gir em função da ordem de parto utilizados neste estudo.

\begin{tabular}{lcccc}
\hline $\begin{array}{c}\text { Ordem } \\
\text { de parto }\end{array}$ & $\begin{array}{c}\text { Peso ao parto } \\
(\mathbf{k g})\end{array}$ & $\begin{array}{c}\text { Período de serviço } \\
(\text { dias) }\end{array}$ & $\begin{array}{c}\text { Intervalo de } \\
\text { partos (dias) }\end{array}$ & $\begin{array}{c}\text { Idade ao parto } \\
\text { (meses) }\end{array}$ \\
\hline Primeiro & $442,4^{\mathrm{d}}$ & $160,4^{\mathrm{a}}$ & $446,0^{\mathrm{a}}$ & 33,7 \\
Segundo & $473,7^{\mathrm{c}}$ & $90,2^{\mathrm{b}}$ & $376,0^{\mathrm{b}}$ & 48,3 \\
Terceiro & $497,2^{\mathrm{b}}$ & $76,2^{\mathrm{b}}$ & $361,4^{\mathrm{b}}$ & 60,7 \\
Quarto & $502,6^{\mathrm{b}}$ & $72,0^{\mathrm{b}}$ & $355,2^{\mathrm{b}}$ & 72,6 \\
Quinto & $500,8^{\mathrm{b}}$ & $89,1^{\mathrm{b}}$ & $375,9^{\mathrm{b}}$ & 84,3 \\
Sexto & $519,9^{\mathrm{a}}$ & $79,9^{\mathrm{b}}$ & $370,1^{\mathrm{b}}$ & 96,6 \\
Sétimo & $529,6^{\mathrm{a}}$ & $96,2^{\mathrm{b}}$ & $382,1^{\mathrm{b}}$ & 108,8 \\
Oitavo & $534,7^{\mathrm{a}}$ & $67,3^{\mathrm{b}}$ & $347,6^{\mathrm{b}}$ & 121,4 \\
Nono & $541,1^{\mathrm{a}}$ & $76,9^{\mathrm{b}}$ & $350,1^{\mathrm{b}}$ & 130,5 \\
\hline
\end{tabular}

Médias seguidas de letras minúsculas distintas na mesma coluna diferem $(\mathrm{P}<0,05)$ pelo teste Scott-Knott Fonte: Oliveira et al. (2012). 
Tabela 3. Índices técnicos e de manejo de vacas F1 Holandês x Gir encontrados na literatura e utilizados neste estudo.

\begin{tabular}{|c|c|}
\hline Itens & Valor \\
\hline Taxa de natalidade ${ }^{1}$ & $98,13 \%$ \\
\hline Intervalo de partos - média 9 partos ${ }^{1}$ & 373,82 dias \\
\hline Taxa de mortalidade de bezerros até 12 meses $^{2}$ & $7,0 \%$ \\
\hline Taxa de mortalidade de vacas - anual ${ }^{2}$ & $1,0 \%$ \\
\hline Produção total na lactação - média 9 partos $^{3}$ & $3.586,75 \mathrm{~kg}$ \\
\hline Duração da lactação - média 9 partos $^{3}$ & 275,23 dias \\
\hline Produção de leite - média por dia $(9 \text { anos })^{3}$ & $13,03 \mathrm{~kg} / \mathrm{dia}$ \\
\hline Peso vaca ao parto - média 9 partos $^{1}$ & 504,66 \\
\hline Taxa de reforma anual - considerando 9 partos & $12 \%$ \\
\hline Consumo de matéria seca cana in natura ${ }^{4}$ & $7,71 \mathrm{~kg}$ \\
\hline Produção de leite/vaca/dia - cana de açúcar in natura ${ }^{4}$ & $11,13 \mathrm{~kg}$ \\
\hline
\end{tabular}

${ }^{1}$ Oliveira et al. (2012); ${ }^{2}$ Campos e Ferreira (2006); ${ }^{3}$ Pereira (2012); ${ }^{4}$ Santos (2011);

Tabela 4. Valores relacionados à comercialização de animais e produtos e aos indicadores mercadológicos utilizados neste estudo.

\begin{tabular}{|c|c|}
\hline Itens & Valor \\
\hline Comercialização do leite & Preço mensal - Cepea ${ }^{1}$ \\
\hline Bezerro(a) - peso médio $175,6 \mathrm{~kg}$ & @ boi - Cepea ${ }^{1}$ \\
\hline Vaca descarte & $17 @$ vaca - Cepea ${ }^{1}$ \\
\hline Novilhas F1 30 meses - gestante 6 meses & $30 @$ boi - Cepea ${ }^{1}$ \\
\hline Novilhas F1 10 meses - desmamada & $20 @$ boi - Cepea $^{1}$ \\
\hline Concentrado - média do período & $\mathrm{R} \$ 0,63 / \mathrm{kg}$ \\
\hline Relação concentrado:leite (acima de 5 kg leite) & $1: 3$ \\
\hline Aluguel de pasto - mensal & 20\%@ boi - Cepea ${ }^{1}$ \\
\hline Custo de produção - cana in natura no cocho ${ }^{2}$ & $\mathrm{R} \$ 51,00 /$ ton. \\
\hline Mão de obra contratada - por pessoa por mês & $\mathrm{SM}+36,8 \%$ de encargos \\
\hline Salário mínimo (SM) - 2011 & $\mathrm{R} \$ 545,00$ \\
\hline Índice de correção de 11/2011 a 09/2013 (IGP-M) & 1,1222637 \\
\hline Taxa real de juros - mensal & $0,5 \%$ \\
\hline Área do sistema de produção & 10 ha \\
\hline Terra por ha & $\mathrm{R} \$ 10.000,00$ \\
\hline Arrendamento - referência & 1 litro leite/dia/ha \\
\hline
\end{tabular}

${ }^{\mathrm{I}}$ Cepea. Região de referência: Minas Gerais (MG). ${ }^{2}$ Valor médio praticado na região no período do estudo.

Para analisar a rentabilidade, primeiramente foi definida a infraestrutura do sistema hipotético de produção de leite e realizado o inventário (cadastro de todos os bens móveis e benfeitorias, bem como as suas particularidades: data e valor de aquisição, vida útil e valor de sucata), conforme utilizado por Lopes et al. (2004).

As informações relacionadas às despesas (mão de obra, alimentação, sanidade etc.) e às receitas (venda de leite e animais) foram estimadas conforme a literatura e registradas em planilhas eletrônicas apropriadas para essa finalidade. As informações mensais relacionadas aos indicadores mercadológicos (remuneração do empresário, arrendamento da terra, taxa real de juros mensal e valor da terra) foram definidas conforme valores vigentes de mercado.

O inventário, bem como as despesas, as receitas e os demais dados foram cadastrados no software Custo Bovino Leite 1.0 (LOPES et al., 2002) visando obter a análise de rentabilidade. Esse software contempla as metodologias de custo total de produção (clásssica) que envolve o custo fixo e variável utilizada por Barros (1948) e o custo operacional proposto por Matsunaga et al. (1976).

Nesse sistema hipotético de produção de leite foi considerado o manejo de duas ordenhas diárias nos primeiros dias de lactação. A simulação 
foi considerar o efeito do manejo de quatro ordenhas em vacas primíparas F1 Holandês x Gir nos primeiros 21 dias de lactação sobre a rentabilidade. No período da manhã, as vacas desse grupo eram inicialmente submetidas a primeira ordenha e somente depois que as demais vacas do rebanho eram ordenhadas é que elas retornavam para a segunda ordenha. No período da tarde, essas vacas eram novamente submetidas a duas ordenhas do mesmo modo como descrito no período da manhã. Os intervalos entre as ordenhas foram, aproximadamente, de duas horas entre a primeira e a segunda, cinco horas entre a segunda e terceira, uma hora e vinte minutos entre a terceira e quarta, e quinze horas e vinte minutos entre a quarta (última do dia) e a primeira ordenha do dia seguinte.

Assim sendo, considerou-se que o inventário e as informações dos indicadores mercadológicos (taxa real de juros, remuneração do empresário, dentre outras) foram iguais às duas alternativas. As despesas referentes à produção de leite foram estimadas e consideradas maiores com o uso de quatro ordenhas. Esse fato foi devido ao item alimentação onerar o custo com o concentrado utilizado para balancear a dieta relativa ao aumento na produção de leite e para os itens mão de obra e energia devido ao maior tempo despendido na ordenha das vacas. Quanto às receitas, estimou-se aumento de $17,28 \%$ no volume de leite produzido pelas vacas em função do uso dessa tecnologia, conforme Ruas et al. (2011).

Os resultados foram tabulados em planilha eletrônica desenvolvida no MS Excel® e comparados por meio de análises estatísticas descritivas, segundo Lopes et al. (2009).

\section{Resultados e Discussão}

O resumo da análise de rentabilidade da atividade leiteira de um sistema de produção de leite com vacas F1 Holandês x Gir utilizando o manejo de duas e de quatro ordenhas no início da lactação sobre a rentabilidade de sistemas de produção de leite com vacas F1 Holandês x Gir pode ser observado na Tabela 5. Houve um aumento de $\mathrm{R} \$ 6.600,61$, equivalente a $2,86 \%$ na receita do sistema de produção de leite com o uso do manejo de quatro ordenhas no início da lactação. Isso pode ser justificado porque, com o mesmo preço de venda do leite e o mesmo valor da receita com animais, considerou-se um aumento de $17,28 \%$ no volume de leite produzido pelas vacas primíparas com o manejo de quatro ordenhas nos primeiros 21 dias da lactação. A implementação desse sistema de manejo determinou maior produção de leite no período e maior receita total. A receita com a venda de leite foi incrementada em $3,62 \%$, aumentando de $\mathrm{R} \$ 182.337,29$ para $\mathrm{R} \$$ 188.937,90, o mesmo acontecendo com a representatividade da venda de leite na receita total que foi elevada em $0,73 \%$, aumentando de $79,14 \%$ para $79,72 \%$.

O custo operacional total (COT) aumentou $1,17 \%$, mas o resultado final foi positivo porque o lucro que era de $\mathrm{R} \$ 60.077,09$ aumentou para $\mathrm{R} \$$ 64.807,38, sendo incrementado em R \$ 4.730,29, valor equivalente a $7,87 \%$. Portanto, foi possível compensar o aumento dos custos do concentrado para a produção de leite, da mão de obra e da energia para o manejo de quatro ordenhas, bem como aumentar a lucratividade.

O ganho bruto foi acrescido em $4,54 \%$ e o líquido em $5,77 \%$, portanto, o manejo com quatro ordenhas no início da lactação mostra viabilidade econômico-financeira do sistema de produção. $\mathrm{O}$ lucro que era de $26,07 \%$ aumentou para $27,34 \%$ e a rentabilidade de $9,8 \%$ foi elevada para $10,55 \%$, correspondendo ao aumento de 4,87\% e 7,58\%, respectivamente. Vale salientar que tanto a lucratividade quanto a rentabilidade foram ainda melhores do que os (nos) valores apresentados, já que o cálculo foi efetuado considerando o custo total (CT) e nele já estão computadas as remunerações com terra, sobre capital investido e sobre o capital de giro. Wall e McFadden (2007) estimaram aumento do lucro líquido em cerca de US\$93,00 por vaca ao ano, quando foram ordenhadas quatro vezes ao dia nas primeiras três semanas da lactação e que posteriormente retornaram a duas ordenhas diárias.

O leite produzido no período aumentou de $211.327 \mathrm{~kg}$ para $217.170 \mathrm{~kg}$, correspondendo a um acréscimo de $2,76 \%$, sendo devido ao aumento de $17,28 \%$ da produção de oito vacas primíparas, as quais haviam parido no período e que foram diariamente ordenhadas por quatro vezes nos primeiros 21 dias de lactação.

Pode-se observar, na Tabela 6 que a proporção da depreciação no COT teve uma ligeira diminuição devido ao aumento da produção de leite no período, promovendo uma diluição desse custo. De acordo com Lopes et al. (2006), aumentando a escala de produção até determinados níveis, o COT por $\mathrm{kg}$ de leite produzido é reduzido devido à otimização da estrutura física da empresa. Já na relação $\mathrm{COE} / \mathrm{COT}$ ocorreu o contrário em razão do 
custo com alimentação, mão de obra e energia. A média da produção diária por vaca acresceu de $11,58 \mathrm{~kg}$ para $11,90 \mathrm{~kg}$, equivalente a $2,76 \%$, portanto, incrementou, na mesma proporção, a produtividade por hectare ao ano, que já era expressiva. O ponto de equilíbrio, ou seja, a quantidade de leite a ser produzida para igualar o CT às receitas diminuiu em 4,97\%, mostrando que, com o mesmo preço de venda e com o COE inferior, menor foi a quantidade de leite a ser produzida para atingir esse equilíbrio.

Considerando a composição do COE, podese verificar na Tabela 7 , que a alimentação aumentou a participação em $9,1 \%$. Tal fato ocorreu em função do maior gasto com o concentrado utilizado para balancear a dieta relativa ao incremento na produção de leite e que, por sua vez, aumentou, em $27,47 \%$, a sua participação no item alimentação do COE, elevando de $21,48 \%$ para 27,38\%. Segundo Smith et al. (2002), com o aumento da produção de leite é preciso suplementar corretamente as vacas para suprir suas necessidades para que não ocorra a perda de peso e do escore de condição corporal ao mobilizar sua reserva corporal.

Tabela 5. Comparativo dos resumos das análises de rentabilidades da atividade leiteira de um sistema de produção de leite com vacas F1 Holandês x Gir com o uso do manejo de duas e de quatro ordenhas no início da lactação, no período de maio de 2011 a abril de 2012.

\begin{tabular}{lccc}
\hline \multicolumn{1}{c}{ Especificação } & $\begin{array}{c}\text { Sistema de } \\
\text { produção com duas } \\
\text { ordenhas }\end{array}$ & $\begin{array}{c}\text { Sistema de } \\
\text { produção com } \\
\text { quatro ordenhas }\end{array}$ & $\begin{array}{c}\text { \% de } \\
\text { variação }\end{array}$ \\
\hline Receitas (R\$) & $230.403,04$ & $237.003,65$ & 2,86 \\
Leite (R\$) & $182.337,29$ & $188.937,90$ & 3,62 \\
Animais (R\$) & $48.065,75$ & $48.065,75$ & 0,00 \\
Outras receitas (R\$) & 0,00 & 0,00 & 0,00 \\
Custo operacional total (COT) (R\$) & $145.348,96$ & $147.043,32$ & 1,17 \\
Custo operacional efetivo (COE) (R\$) & $123.171,04$ & $124.865,40$ & 1,38 \\
Custo com depreciação (CD) (R\$) & $22.177,92$ & $22.177,92$ & 0,00 \\
Mão de obra familiar (R\$) & 0,00 & 0,00 & 0,00 \\
Custo total (CT) (R\$) & $170.325,95$ & $172.196,27$ & 1,10 \\
Custos fixos (CF) (R\$) & $46.065,49$ & $46.065,49$ & 0,00 \\
Remuneração da terra (R\$) & 112,00 & 112,00 & 0,00 \\
Remuneração do capital investido (R\$) & $22.832,31$ & $22.832,31$ & 0,00 \\
Remuneração do empresário (R\$) & 0,00 & 0,00 & 0,00 \\
Impostos considerados fixos (R\$) & 943,26 & 943,26 & 0,00 \\
Depreciação (R\$) & $22.177,92$ & $22.177,92$ & 0,00 \\
Custos variáveis (CV) (R\$) & $124.260,46$ & $126.130,78$ & 1,51 \\
Custo operacional efetivo (s/imp.) (R\$) & $122.227,78$ & $123.922,14$ & 1,39 \\
Remuneração do capital de giro (R\$) & $2.032,68$ & $2.208,64$ & 8,66 \\
Mão de obra familiar (R\$) & 0,00 & 0,00 & 0,00 \\
Margem bruta (R\$) & $108.175,26$ & $113.081,51$ & 4,54 \\
Margem líquida (R\$) & $85.054,08$ & $89.960,33$ & 5,77 \\
Resultado (lucro ou prejuízo)(R\$) & $60.077,09$ & $64.807,38$ & 7,87 \\
Lucratividade (\%) & 26,07 & 27,34 & 4,87 \\
Rentabilidade (\%) & 9,80 & 10,55 & 7,58 \\
Leite produzido total (kg) & $211.327,00$ & $217.170,00$ & 2,76 \\
\hline
\end{tabular}


Tabela 6. Índices técnicos / gerenciais do sistema de produção de leite com o uso do manejo de duas e de quatro ordenhas no início da lactação no período de maio de 2011 a abril de 2012.

\begin{tabular}{lcc}
\hline \multicolumn{1}{c}{ Especificação } & $\begin{array}{c}\text { Sistema de produção } \\
\text { com duas ordenhas }\end{array}$ & $\begin{array}{c}\text { Sistema de produção } \\
\text { com quatro ordenhas }\end{array}$ \\
\hline Depreciação / COT (\%) & 15,26 & 15,08 \\
COE / COT (\%) & 84,09 & 84,28 \\
Mão de obra familiar / COT (\%) & 0,00 & 0,00 \\
Custo fixo / Custo total (\%) & 27,05 & 26,75 \\
Custo variável / Custo total (\%) & 72,95 & 73,25 \\
Depreciação / Custo total (\%) & 13,02 & 12,88 \\
Produtividade animal / dia (kg de leite) & 11,58 & 11,90 \\
Produtividade animal / ha/ ano (kg de leite) & $21.132,70$ & $21.717,00$ \\
Produção diária vendida (kg de leite) & 578,98 & 594,99 \\
Produção diária (kg de leite) & 578,98 & 594,99 \\
Ponto de equilíbrio /kg leite / dia (kg de leite) & 459,23 & 436,39 \\
Quantidade de vacas em lactação / ha (un) & 5,00 & 5,00 \\
Produção de leite / mão de obra (kg / serviço) & 289,49 & 297,49 \\
Relação matrizes / homem (un) & 34,00 & 34,00 \\
Relação total do rebanho / homem (un) & 65,00 & 65,00 \\
Quantidade de mão de obra (un) & 2,00 & 2,00 \\
\hline
\end{tabular}

Tabela 7. Contribuição de cada item no custo operacional efetivo do sistema de produção de leite com o uso do manejo de duas e de quatro ordenhas no início da lactação, em \%, no período de maio de 2011 a abril de 2012.

\begin{tabular}{|c|c|c|}
\hline Especificação & $\begin{array}{c}\text { Sistema de produção com } \\
\text { duas ordenhas }\end{array}$ & $\begin{array}{l}\text { Sistema de produção } \\
\text { com quatro ordenhas }\end{array}$ \\
\hline Alimentação & 44,60 & 48,66 \\
\hline Concentrado & 21,48 & 27,38 \\
\hline Sal mineral & 1,05 & 0,97 \\
\hline Volumoso & 22,07 & 20,31 \\
\hline Mão de obra & 14,64 & 13,78 \\
\hline Sanidade & 3,67 & 3,38 \\
\hline Ordenha & 4,89 & 4,50 \\
\hline Reprodução & 1,75 & 1,61 \\
\hline Energia & 4,32 & 4,02 \\
\hline Despesas diversas & 26,14 & 24,05 \\
\hline
\end{tabular}

Quanto à mão de obra para realizar as duas ordenhas, houve um ligeiro aumento despendido em horas trabalhadas na sala de ordenha, entretanto, o percentual de participação no $\mathrm{COE}$ diminuiu proporcionalmente $(5,87 \%)$ porque $\mathrm{O}$ volume de leite produzido aumentou. Vale salientar que não houve aumento na quantidade de turnos de ordenha, continuando dois turnos por dia. Assim sendo, o acréscimo no custo da mão de obra foi proporcionalmente menor porque não incidiu nos encargos trabalhistas, como a hora extra e o adicional noturno.

Os custos com materiais utilizados na sala de ordenha para obtenção higiênica do leite considerados no item ordenha, tiveram um acréscimo muito pequeno em razão das ordenhas aumentadas terem sido ato contínuo às ordenhas realizadas no sistema de produção com duas ordenhas. Dessa maneira, esses custos não apresentaram diferença expressiva no valor monetário, entretanto, o valor percentual apresentou uma pequena diminuição em função do aumento do leite produzido.

A manutenção dos equipamentos de ordenha foi realizada em períodos pré-determinados e com o uso do manejo de quatro ordenhas não houve necessidade de alteração no proposto para o sistema de produção com duas ordenhas. Logo, 
esses custos continuaram com o mesmo valor monetário, no entanto, o valor percentual teve uma pequena diminuição em função do aumento do leite produzido. Segundo Cardoso e Costa (2004), considerando o período de tempo, as mangueiras de leite devem ser substituídas a cada ano, as de vácuo de dois em dois anos e os insufladores a cada seis meses de uso.

$\mathrm{O}$ custo com energia diminuiu proporcionalmente $(6,94 \%)$ devido ao aumento da escala de produção, uma vez que houve maior produção de leite por unidade de energia. Isto pode ser observado principalmente no momento da limpeza e higienização da ordenhadeira, pois o tempo que ficou em funcionamento foi o mesmo, contudo, o volume de leite produzido no turno de ordenha foi maior. Por outro lado, a participação da energia foi responsável por 3,46\% do COT, valor bem acima de 1,54\% obtido por Barbosa et al. (2013) na implementação de um turno referente à terceira ordenha em estudo com três rebanhos produzindo, em média, $465,32 \mathrm{~kg}$ de leite por dia.
Essa diferença de valores pode ser justificada porque esses autores fizeram os cálculos apenas da terceira ordenha e, nesse caso, a participação da mão de obra foi muito mais expressiva, diminuindo a participação proporcional do custo com energia.

No que concerne às despesas diversas, o percentual de 24,05\% está alto e bem acima da média de 10,83\% encontrada por Lopes et al. (2004). Isso pode ser explicado pelo alto valor do frete, o qual está relacionado a fatores externos, como qualidade das estradas e distância percorrida, principalmente.

Ao subtrair o CT custo total do preço médio do leite, pode-se observar (Tabela 8) que houve lucro de $\mathrm{R} \$ 0,05$ por $\mathrm{kg}$ de leite do sistema de produção com duas ordenhas e de $\mathrm{R} \$ 0,08$ do sistema com o uso de quatro ordenhas. Mesmo apresentando aumento dos custos, os quais, de certa forma, foram considerados ínfimos, o sistema de quatro ordenhas apresentou menor CT por $\mathrm{kg}$ de leite devido ao aumento na produção, fato que proporcionou maior lucro por $\mathrm{kg}$ de leite.

Tabela 8. Custos médios de produção, por quilograma de leite, do sistema de produção de leite com o uso do manejo de duas e de quatro ordenhas no início da lactação, em $\mathrm{R} \$ / \mathrm{kg}$, no período de maio de 2011 a abril de 2012.

\begin{tabular}{lcc}
\hline \multicolumn{1}{c}{ Especificação } & $\begin{array}{c}\text { Sistema de produção } \\
\text { com duas ordenhas }\end{array}$ & $\begin{array}{c}\text { Sistema de produção } \\
\text { com quatro ordenhas }\end{array}$ \\
\hline Preço médio do leite & 0,86 & 0,86 \\
Custo operacional total & 0,69 & 0,67 \\
Custo operacional efetivo & 0,58 & 0,56 \\
Custo total & 0,81 & 0,78 \\
Custo fixo & 0,22 & 0,21 \\
Custo variável & 0,59 & 0,57 \\
\hline
\end{tabular}

\section{Conclusão}

$\mathrm{O}$ uso do manejo de quatro ordenhas nos primeiros 21 dias de lactação incrementa os resultados econômico-financeiros e aumenta a rentabilidade do sistema de produção de leite de vacas F1 Holandês x Gir confinadas durante o período da seca e alimentadas com cana-de-açúcar in natura (Saccharum officinarum L.) enriquecida com ureia e sulfato de amônio.

\section{Conflito de Interesse}

Os autores declaram não existir conflito de interesse.

\section{Agradecimentos}

Os autores agradecem ao Conselho Nacional de Desenvolvimento Científico e Tecnológico $\mathrm{CNPq}$ pelo apoio na realização desta pesquisa.

\section{Referências}

Barbosa, G.L.; Lopes, M.A.; Nogueira, T.M.; Costa, G.M.; Albuquerque, F.T. Viabilidade econômica da terceira ordenha em sistemas de produção de leite com ordenhadeira tipo circuito aberto. Arquivo Brasileiro de Medicina Veterinária e Zootecnia, 65(4): 1123-1130, 2013.

Barros, H. Economia agrária. Lisboa: Sá da Costa, 1948, 348 p. 
Cardoso, I.S.; Costa, U.S. Ordenha mecânica. 2. ed. Brasília: SENAR, 2004. 36 p.

Campos, A.L.T.; Ferreira, A.M. Composição no rebanho e sua importância no manejo. 2006. revisada e atualizada. Instrução técnica para o produtor de leite. Embrapa, 2006.

Lima, J.A.M; Coelho, S.G; Ruas, J.R.M; Lana, A.M.Q; Saturnino, H.M; Reis, R.B. Efeito do aumento da frequência de ordenhas no início da lactação sobre produção, composição do leite e características reprodutivas de vacas mestiças Holandês-Zebu. Arquivo Brasileiro de Medicina Veterinária e Zootecnia, v. 63(5): 1160-1166, 2011.

Lopes, M.A.; Campello; R.P.; Carvalho, F.M. Custo bovino leite 1.0: software de controle de custos para a atividade leiteira. Revista Brasileira Agroinformática, 4: 102-115, 2002.

Lopes, M.A.; Dias, A.S.; Carvalho, F.M.; Lima, A.L.R.; Cardoso, M.G.; Carmo, E.A. Resultados econômicos de sistemas de produção de leite com diferentes níveis tecnológicos na região de Lavras (MG) nos anos 2004 e 2005. Revista Ciência e Agrotecnologia, v. 33(1): 252-260, 2009.

Lopes, M.A.; Lima, A.L.R.; Carvalho, F.M.; Reis, R.P.; Santos, Í.C.; Saraiva, F.H. Controle gerencial e estudo da rentabilidade de sistemas de produção de leite na região de Lavras (MG). Revista Ciência e Agrotecnologia, v. 4: 883-892, 2004.

Lopes, M.A.; Lima, A.L.R.; Carvalho, F.M.; Reis. R.P.; Santos, I.C.; Saraiva, F.H. Efeito da escala de produção nos resultados econômicos de sistemas de produção de leite na região de Lavras (MG): um estudo multicasos. Boletim da Indústria Animal, 63(3), 177-188, 2006.
Matsunaga, M.; Bemelmans, P.F.; Toledo, P.E.N. Metodologia de custo de produção utilizado pelo IEA. São Paulo: Agricultura em São Paulo, 1976, p. 123-139.

Oliveira, P.A.; Ruas, J.R.M.; Frota, L.M. Avaliação de características produtivas e reprodutivas de vacas F1 Holandês x Gir. In: SEMINÁRIO DE INICIAÇÃO CIENTÍFICA E TECNOLÓGICA, 9. 2012, Belo Horizonte. Resumos... Belo Horizonte: EPAMIG, 2012. p.1-4.

Pereira, M.E.G. Produção de leite de quatro grupos genéticos f1 holandês x zebu. 2012 . 78 p. Dissertação (Mestrado em Zootecnia) Universidade Estadual de Montes Claros, Janaúba-MG, 2012.

Ruas, J.R.M.; Guimarães, A.S.; Queiroz, D.S.; Silva, E.A.; Pereira, M.E.G., Frota, L.M. Influência do aumento da frequência de ordenhas no início da lactação sobre produção de leite de vacas primíparas F1 Holandês $\mathrm{x}$ Zebu (F1 HZ). In: REUNIÃO ANUAL DA SOCIEDADE BRASILEIRA DE ZOOTECNIA, 48. 2011, Belém. Anais... Belém: SBZ, 2011. 1 Cd-rom.

Santos, S.A. Curvas de lactação e consumo de vacas F1 Holandês $x$ Zebu em pastejo e confinamento. 2011.212 p. Tese (Doutorado) - Universidade Federal de Viçosa, ViçosaMG, 2011.

Smith, J.W.; Ely, L.O.; Graves, W.M.; Gilson, W.D. Effect of milking frequency on DHI performance measures. Journal of Dairy Science, 85(12): 3526-3533, 2002.

Wall, E.H.; McFadden, T.B. The milk yield response to frequent milking in early lactation of dairy cows is locally regulated. Journal of Dairy Science, 90: 716-720, 2007. 